\begin{tabular}{|c|c|c|}
\hline $\begin{array}{l}\text { PKS } \\
\text { PUBLIC } \\
\text { KNOLLEDGE } \\
\text { PROJECT }\end{array}$ & $\begin{array}{c}\text { REVISTA DE GEOGRAFIA } \\
\text { (RECIFE) } \\
\text { http://www.revista.ufpe.br/revistageografia }\end{array}$ & $\begin{array}{l}\text { OJS } \\
\frac{\text { OJEN }}{\text { OPOUNAL }} \\
\text { SYSTEMS }\end{array}$ \\
\hline
\end{tabular}

\title{
UTILIZAÇÃO DO MODELO PRESSÃO-ESTADO-RESPOSTA NA AVALIAÇÃO DE INDICADORES AMBIENTAIS DO MUNICÍPIO DE BREJO DA MADRE DE DEUS - PE
}

\author{
Helenize Carlos de Macêdo ${ }^{1}$, Maria Fernanda Abrantes Torres ${ }^{2}$ \\ ${ }^{1}$ Universidade Federal de Pernambuco (UFPE).E-mail: helen_ane@hotmail.com \\ ${ }^{2}$ Universidade Federal de Pernambuco (UFPE).E-mail: daetorres@hotmail.com
}

Artigo recebido em $30 / 05 / 2018$ e aceito em 02 / 11 / 2018

\begin{abstract}
RESUMO
O presente trabalho teve como objetivo avaliar os indicadores ambientais do Município de Brejo da Madre de Deus - PE, através do método de mensuração da sustentabilidade pressão-estado-resposta, tendo em vista contribuir com informações que possam subsidiar o poder público no estabelecimento de políticas públicas que promovam o desenvolvimento sustentável. Para tanto, utilizou-se alguns procedimentos metodológicos: seleção de indicadores a partir do conhecimento e análise da área de estudo, suporte de referenciais teóricos e técnicos; revisão bibliográfica, produção de material geocartográfico, visitas de campo e coleta de dados em órgãos públicos. Os resultados apontam a necessidade do estabelecimento de uma política ambiental municipal que possa solucionar os problemas verificados através dos indicadores de pressão e estado, melhorando a qualidade do meio ambiente.
\end{abstract}

Palavras-chave: Indicadores Ambientais; Mensuração da Sustentabilidade; Políticas Públicas; Desenvolvimento Sustentável.

\section{THE USE OF MODEL "PRESSURE-STATE-RESPONSE" IN EVALUATION OF ENVIRONMENTAL INDICATORS OF BREJO DA MADRE DE DEUS - PE}

\begin{abstract}
The objective of this study is to evaluate the environmental indicators of the Municipality of Brejo da Madre de Deus - PE, through the measurement method of pressure-state-response sustainability, with the aim of contributing information that can subsidize public power in the establishment of public policies that promote sustainable development. For that, some methodological procedures were used: selection of indicators based on knowledge and analysis of the study area, support of theoretical and technical references; bibliographic review; production of geocartographic material; field visits and data collection in public agencies. The results point out the need to establish a municipal environmental policy that can solve the problems verified through indicators of pressure and state, improving the quality of the environment.
\end{abstract}

Keywords: Environmental Indicators; Sustainability Measurement; Public Policies; Sustainable Development.

\section{INTRODUÇÃO}

A busca pelo equilíbrio da relação sociedade-natureza tem sido objeto de discussão na atualidade em virtude dos problemas ambientais decorrentes do uso predatório dos recursos naturais. De acordo com Bragatto et al. (2012), o domínio do meio ambiente pelo 
homem ocasionou o desequilíbrio dos ecossistemas, originando o conflito denominado de crise ambiental. O processo de degradação ambiental é complexo e necessita do emprego de medidas de gestão e controle que perpassam por ações e soluções integradas de gestão ambiental, visando minimizar os impactos ambientais.

Neste contexto, a utilização de mecanismos que possibilitem subsidiar as ações da sociedade em direção à sustentabilidade dos ecossistemas é fundamental para equacionar a relação entre crescimento econômico e a manutenção dos recursos naturais. Na concepção de Couto (2007), a construção de um modelo de desenvolvimento, sob a perspectiva da harmonia em relação às bases econômicas e a capacidade de suporte do meio ambiente, implica em um amplo levantamento de dados e informações representativas das diversas dimensões dos sistemas produtivos e sobre o funcionamento dos sistemas ambientais pelos agentes tomadores de decisões.

Dentre estes instrumentos, que visam contribuir para a avaliação da sustentabilidade e o levantamento de informações sobre os sistemas ambientais, destacam-se os indicadores de sustentabilidade, definidos como parâmetros que fornecem ou descrevem o estado de um fenômeno, ambiente ou zona geográfica (OECD, 2003). Segundo Hammond et al. (1995), o termo indicador origina-se do latim indicare, que significa descobrir, apontar, anunciar, estimar, comunicando acerca do progresso em direção a uma meta pré-estabelecida, como, por exemplo, o desenvolvimento sustentável.

Para Van Bellen (2002), o objetivo principal dos indicadores é o de agregar informações de maneira que seu significado fique mais aparente. Os indicadores simplificam as informações sobre fenômenos complexos visando melhorar o processo de comunicação. É através das informações adquiridas mediante o uso dos indicadores que poderão ser subsidiadas as etapas de planejamento, implantação e acompanhamento das políticas de gestão ambiental voltadas para a utilização adequada dos recursos naturais e o ordenamento das intervenções nos sistemas ambientais (KEMERICH; RITTER; BORBA, 2014).

Mediante o exposto, o presente estudo tem como objetivo avaliar indicadores ambientais do Município de Brejo da Madre de Deus - PE através do método de mensuração da sustentabilidade pressão-estado-resposta, tendo em vista contribuir com informações que possam auxiliar os gestores públicos e a sociedade na tomada de decisões que promovam o desenvolvimento sustentável. Ademais, pretende-se colaborar com os estudos que envolvem indicadores e sistemas de mensuração da sustentabilidade, abordagens ainda pouco pesquisadas no Brasil. 


\section{SISTEMAS DE INDICADORES DE SUSTENTABILIDADE AMBIENTAL: ASPECTOS CONCEITUAIS}

A utilização de indicadores na mensuração da sustentabilidade começou nas décadas de 1970 e 1980, quando foram divulgados os primeiros relatórios ambientais em nível mundial, provocando os órgãos governamentais e organizações internacionais na construção e aplicação de indicadores. O governo holandês foi o pioneiro no emprego de indicadores ambientais, em 1989, visando avaliar o Plano de Política Ambiental Nacional (HAMMOND et al., 1995).

Para Marzall e Almeida (2000), na última década vem crescendo a busca por indicadores de sustentabilidade por parte de instituições governamentais, ONGs, institutos de pesquisas e universidades em todo o mundo. Muitas conferências têm sido realizadas em torno do tema, assim como outras iniciativas de pesquisadores vinculados a instituições governamentais e acadêmicas no tratamento da questão, porém pouco se tem de concreto, tendo em vista ser um objeto recente para a comunidade científica.

Na concepção de Gomes e Malheiros (2012), através da utilização dos indicadores de sustentabilidade é possível analisar condições diversas do sistema estudado, permitindo o entendimento das interfaces da sustentabilidade e de tendências, constituindo-se em uma ferramenta no processo decisório, na construção de políticas públicas e efetivação de práticas sustentáveis.

Segundo Bragatto et al. (2012), compatibilizar desenvolvimento e meio ambiente significa considerar os problemas dentro de um contínuo processo de planejamento, atendendo-se as exigências de ambos. Para tanto, é importante o estabelecimento de sistemas de medição e monitoramento, sendo que para o funcionamento adequado destes sistemas é fundamental o uso de indicadores. Os indicadores de sustentabilidade ambiental são ferramentas essenciais para guiar ações e subsidiar o acompanhamento e avaliação do progresso alcançado rumo ao desenvolvimento sustentável.

Existem diversos modelos que podem ser aplicados para o estudo de indicadores ambientais. Dentre os modelos/métodos existentes destacam-se o Modelo Pressão - Estado Resposta (PER), desenvolvido e adotado pela Organização para Cooperação e Desenvolvimento Econômico (OCDE); O Modelo Pressão - Estado - Impacto - Resposta (PEIR), empregado pelo Programa de Desenvolvimento das Nações Unidas e Meio Ambiente (PNUMA); Modelo Força Motriz - Estado - Resposta (FER), utilizado pela Comissão de 
Desenvolvimento das Nações Unidas para o Desenvolvimento Sustentável (UNCSD) (SOUZA; SILVA, 2014).

Os indicadores foram desenvolvidos para atender determinados objetivos, sendo importante classificá-los de acordo com modelos de mensuração preestabelecidos, tendo em vista compreender os parâmetros que devem ser utilizados para a obtenção de uma melhor descrição do sistema analisado e quais os indicadores devem ser agrupados para obter um melhor resultado (SOUZA; SILVA, 2014; BAKKES et al., 1994).

Neste trabalho, optou-se pelo uso do Modelo Pressão - Estado - Resposta devido a sua ampla aplicabilidade nos estudos de sistemas ambientais, atendendo aos objetivos propostos para a realização desta pesquisa. De acordo com Carvalho et al. (2008), o PER é o modelo mais utilizado internacionalmente para a apresentação e análise de estatísticas ambientais, porém ainda é pouco aplicado no Brasil. Esse modelo permite relacionar cada problema ambiental às suas respectivas causas e ações/políticas destinadas para combatê-los.

\section{O modelo pressão-estado-resposta (PER)}

O Modelo Pressão-Estado-Resposta foi desenvolvido pela Organização para Cooperação e Desenvolvimento Econômico (OCDE), sendo baseado no conceito de causalidade, no qual as atividades antrópicas exercem pressão sobre o ambiente causando alterações na qualidade e quantidade dos recursos naturais, comprometendo o seu estado, e a sociedade responde a essas mudanças através de políticas ambientais, econômicas e setoriais. Uma de suas principais vantagens é evidenciar os elos entre a atividade humana e o meio ambiente, permitindo aos agentes públicos a visualização da interdependência das questões ambientais com outras - sociais, econômicas (OCDE, 1993).

Neste modelo, os indicadores e estatísticas relativas a cada tema estão divididos em três categorias, conforme Carvalho et al. (2008):

-PRESSÃO: Estes indicadores apresentam as pressões que as atividades humanas exercem sobre o meio ambiente (energia, transporte, indústria, agricultura). Exemplo: emissão de poluentes oriundos de fábricas e veículos automotores.

-ESTADO: São aqueles indicadores que expressam as condições do meio ambiente (ar, água, solo, outros), tanto em relação aos aspectos quantitativos como qualitativos, sendo o objetivo final da política melhorar esses indicadores. Exemplo: índices de qualidade do ar. 
-RESPOSTA: Os indicadores de resposta revelam as ações da sociedade às mudanças no meio ambiente. Trata-se das medidas tomadas por agentes econômicos e ambientais (governo, famílias, empresas) para diminuir ou anular as pressões ambientais.

O Modelo PER proporciona uma visão conjunta dos vários componentes de um determinado problema ambiental, facilitando o diagnóstico do problema e a elaboração da política pública adequada à realidade apresentada. Ademais, além da constatação da degradação ambiental, revela o seu impacto, suas causas, o que está por trás dessas causas e as ações que estão sendo executadas para mudar a situação encontrada (CARVALHO, 2007). No entanto, como todos os modelos, o PER apresenta fragilidades. De acordo com Martinez (2001), a principal crítica a estes métodos reside na indução da leitura de uma simples relação de causalidade linear, causando uma simplificação complexa que envolve causalidades múltiplas.

Nesse sentido, é importante a constante atualização e estudo de adaptações para que estes modelos superem suas fragilidades e possam contribuir de forma eficaz para a compreensão da relação sociedade e natureza, em busca de seu equilíbrio e na promoção da sustentabilidade dos sistemas ambientais.

\section{MATERIAIS E MÉTODOS}

\section{Caracterização da Área de Estudo}

O município de Brejo da Madre de Deus - PE (Figura 1) foi selecionado como foco da presente pesquisa por apresentar um cenário associado ao desenvolvimento de atividades diversas como a agricultura, o turismo e o comércio, destacando-se em escala regional. Nesse sentido, se faz necessário compreender como os diversos atores sociais estão interagindo com a natureza, através da avaliação de indicadores socioambientais.

O Município de Brejo da Madre de Deus está localizado na mesorregião do Agreste e na microrregião do Vale do Ipojuca do Estado de Pernambuco, limita-se ao norte, pelos municípios de Santa Cruz do Capibaribe e Taquaritinga do Norte; ao sul, por Belo Jardim, Tacaimbó e São Caetano; ao leste, por Caruaru e Toritama e, ao oeste, por Jataúba. A área encontra-se entre os paralelos $08^{\circ} 08^{\prime} 00^{\prime \prime} \mathrm{S}$ e $08^{\circ} 10^{\prime} 00^{\prime} \mathrm{S}$ e os meridianos $36^{\circ} 20^{\prime} 00^{\prime \prime} \mathrm{W}$ e $36^{\circ} 10^{\prime} 00^{\prime} \mathrm{W}$, perfazendo uma superfície de 782,69 $\mathrm{km}^{2}$, situando-se nos domínios da Bacia Hidrográfica do Rio Capibaribe.

Em relação aos aspectos climáticos, o município apresenta tipo de clima Tropical Semiárido com chuvas de verão; o período chuvoso inicia em novembro e termina em abril, 
com precipitação média anual de $431,8 \mathrm{~mm}$ e temperatura média anual de $22{ }^{\circ} \mathrm{C}$. No que diz respeito às conformações geomorfológicas e pedológicas, a área caracteriza-se por apresentar Patamares Compridos e Baixas Vertentes, Planossolos mal drenados, fertilidade natural média e problemas de acúmulo de sais; Topos e Altas Vertentes com solos Bruno não Cálcicos, rasos e fertilidade natural alta; Topos e Altas Vertentes do relevo ondulado com solos podzólicos drenados, com fertilidade natural média; Nas Elevações Residuais destacam-se os solos Litólicos, rasos, pedregosos e fertilidade natural média (BRASIL, 2005).

Figura 1: Localização do Município de Brejo da Madre de Deus no Estado de Pernambuco. MAPA DE LOCALIZAÇÃO DO MUNICÍPIO DE BREJO DA MLADE DE DEUS - PE

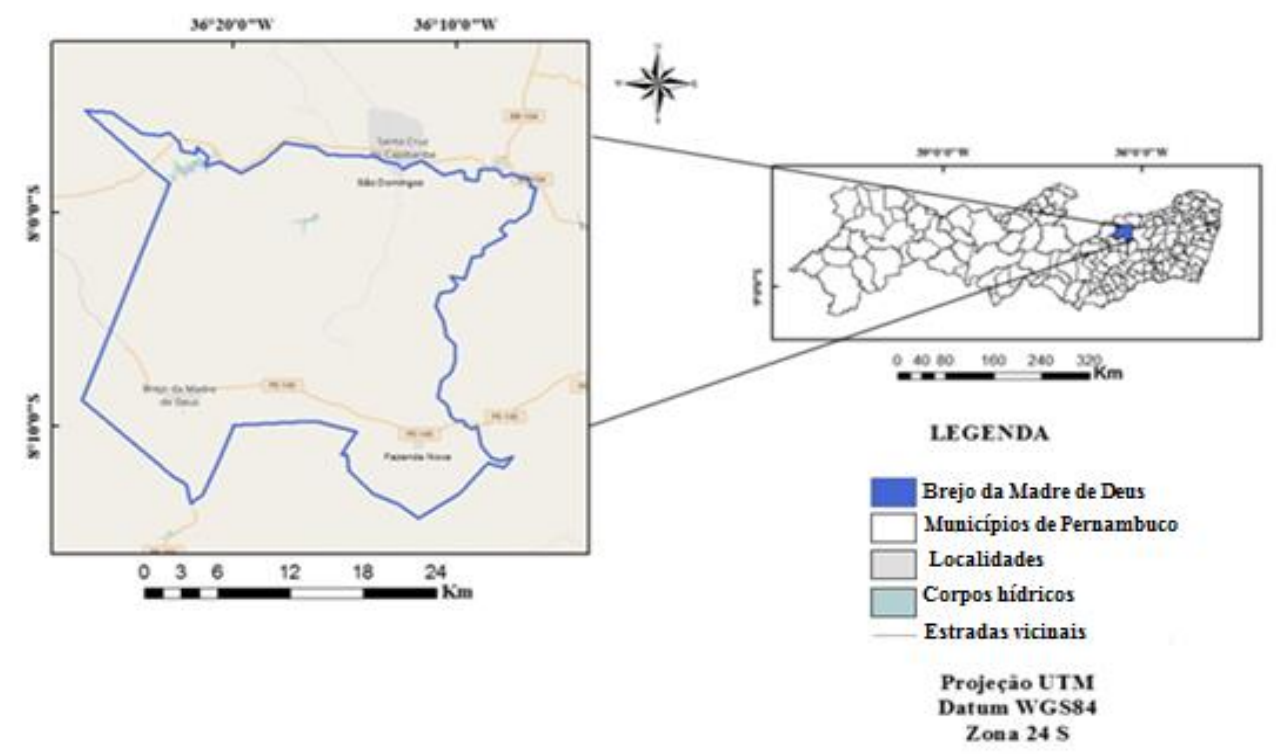

Fonte: IBGE, 2015. Adaptado pelos autores.

No contexto geológico regional, o Município de Brejo da Madre de Deus se insere na Província da Borborema, que compreende os terrenos do Nordeste do Brasil submetidos à orogênese brasiliana. $\mathrm{O}$ maciço da Borborema constitui-se de rochas cristalinas de diferentes tipos, como Gnaisses, Xistos, e intercalações de calcários cristalinos, todos atravessados por massas plutônicas (MELO, 2008).

Geologicamente, destaca-se na região o corpo granítico do Batólito Brejo da Madre de Deus, integrante do Batólito Caruaru-Arcoverde, sendo o maior corpo da associação cálcioalcalina de alto potássio da Província Borborema, situado entre os Municípios de Brejo da Madre de Deus e Belo Jardim. As rochas encaixantes do Batólito Brejo da Madre de Deus são ao norte, ortognaisses graníticos a dioríticos e migmatitos, ao sul, biotita xistos granatíferos, paragnaisses e ortognaisses graníticos a granodioríticos (MELO, 2002). 
Em se tratando da cobertura vegetal, no município de Brejo da Madre de Deus, apresenta-se intrinsecamente relacionada às condições climáticas e edáficas da região. Essas condições são relevantes para a formação das estruturas vegetais, como no porte e diâmetro das espécies, o número de estratos, a diversidade de espécies.

Nesse sentido, na sede municipal, que apresenta altitude elevada (650 m) e clima mais úmido, ocorre uma vegetação distinta, composta por uma comunidade fitológica em que predominam espécies típicas de brejos de altitude. Porém, nas áreas do município onde se destaca o clima semiárido encontram-se as espécies vegetais típicas da Caatinga (SILVA, 2007). Assim, a vegetação de Brejo da Madre de Deus é composta de caatinga hiperxerófila em áreas de clima semiárido, e trechos de florestas caducifólias, que correspondem às áreas de relevo mais elevado, os brejos de altitude.

\section{METODOLOGIA}

Visando alcançar os objetivos propostos neste trabalho foram utilizados alguns procedimentos metodológicos importantes para a execução da pesquisa: seleção de indicadores a partir do conhecimento e análise da área de estudo, suporte de referenciais teóricos e técnicos, revisão bibliográfica, produção de material geocartográfico, visitas de campo e coleta de dados em órgãos públicos

Inicialmente, foi realizada revisão bibliográfica, na qual foi feita a seleção de materiais sobre o tema pesquisado, bem como de pesquisas e publicações sobre a área de estudo, disponíveis em livros e na internet.

Para a elaboração do mapa de Índice de Vegetação por Diferença Normalizada (NDVI) do município de Brejo da Madre de Deus foi necessário captar informações georreferenciadas, associadas com análises técnicas, tendo em vista identificar e monitorar mudanças na paisagem. Nesse sentido, utilizou-se o software Arcgis 9.3, licenciado para o Laboratório de Geografia Física Aplicada da UFPE, e de imagens multiespectrais do Landsat 8 TM (Thematic Mapper), referentes à órbita 215 e ao ponto 065, com data de passagem do dia 14/11/2015 e horário de 12:35 h, disponibilizadas gratuitamente através do catálogo de imagens do Serviço de Levantamento Geológico Americano -United State Geological Survey (USGS). Este período da cena corresponde ao final da estação seca e início da estação chuvosa no município estudado.

A realização de incursões de campo foi fundamental para avaliar as condições ambientais do município, coletar informações em órgãos públicos, verificar as informações 
obtidas por meio de georreferenciamento e definir pontos de poluição. Nesta etapa também foi feita entrevista junto à Assessoria da Secretaria de Agricultura e Meio Ambiente da Prefeitura de Brejo da Madre de Deus, tendo em vista obter informações sobre os problemas ambientais e as respostas dos agentes públicos para solucionar os mesmos

O índice de vegetação utilizado foi o NDVI (Normalized Difference Vegetation Index) ou Índice de Vegetação por Diferença Normalizada (IVDN), em português. Este índice consiste em uma equação que apresenta como variáveis as bandas do vermelho e infravermelho próximo, como se pode demonstrar:

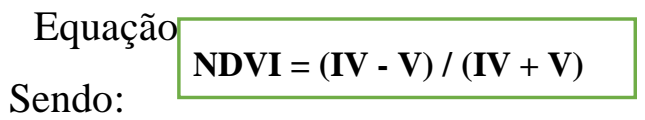

IV - Refletância da banda no Infravermelho Próximo.

V - Refletância da banda no Vermelho.

Fórmula no Raster Calculator:

NDVI $=($ Float $([$ B5 $])-$ Float $([$ B4 $])) /($ Float $([$ B5 $])+$ Float $([\mathbf{B} 4]))$

O resultado do produto gerado do NDVI exibe valores que variam de -1 a 1 , de modo que quanto mais próximo do 1, maior a presença de vegetação, e quanto mais próximo do -1, maior incidência/presença de solos descobertos, formações rochosas e recursos hídricos.

Os indicadores foram definidos de acordo com o Método Pressão-Estado-Resposta PER, a partir do conhecimento e análise da área de estudo, do suporte de referenciais teóricos e técnicos. Além disso, buscaram-se na seleção dos indicadores alguns critérios, como: ser significativo, estar de acordo com o enfoque de estudo e permitir uma fácil interpretação da realidade analisada. Em relação à análise dos indicadores, tomou-se por base as informações disponíveis, classificando-os enquanto favoráveis ou desfavoráveis à sustentabilidade .

\section{RESULTADOS E DISCUSSÃO}

Através da análise e observação da área de estudo, e dos demais procedimentos metodológicos empregados na realização deste trabalho, foram definidos os principais indicadores ambientais para as dimensões do Modelo PER relacionados ao município de Brejo da Madre de Deus - PE. Os resultados da aplicação do PER no município buscaram identificar os problemas avaliados em cada dimensão, o estado dos recursos naturais e as ações que os órgãos públicos vêm promovendo para fomentar a sustentabilidade ambiental. Pressão 
Os indicadores de pressão descrevem o uso predatório dos recursos naturais no município, provocando degradações ambientais. Os principais problemas identificados referem-se ao saneamento básico, à deposição de resíduos sólidos no meio ambiente sem tratamento, ao desmatamento em áreas de APP's e em outras áreas, à extração de areia em leitos de rios e ao uso desordenado de agrotóxicos e insumos químicos na atividade agrícola. Estado

Os indicadores de Estado demonstram as implicações quali-quantitativas do ambiente, revelando as implicações decorrentes das pressões ambientais, ressaltando os principais problemas em relação à poluição das águas e dos solos, além das implicações dessas pressões sobre a vegetação e a fauna. Nesse sentido, o primeiro passo consistiu no diagnóstico dos indicadores, através de visitas de campo, levantamentos de dados em órgãos públicos, verificando-se a situação apresentada segundo cada indicador e as suas possíveis consequências no meio ambiente:

\section{$\underline{\text { Saneamento Básico e Resíduos Sólidos }}$}

Em relação ao indicador saneamento básico, verificou-se uma situação crítica, apresentando os piores resultados referente à destinação adequada dos resíduos sólidos. No município não existem aterros sanitários e estações de tratamento de esgoto, apesar de haver sistema de coleta de lixo doméstico em $77,7 \%$ e de coleta de esgoto em $41,2 \%$ dos domicílios (SNIS, 2013), e os resíduos sólidos são depositados diretamente no meio ambiente. De acordo com dados da Assessoria da Secretaria de Agricultura e Meio Ambiente de Brejo da Madre de Deus (2016), atualmente existem quatro lixões no município e o esgotamento coletado é lançado nos corpos de água, como o Rio Laranjeiras e outros riachos.

Estes dados revelam a falta de aplicação das políticas públicas existentes, tendo em vista que no município existem planos elaborados na área de saneamento básico e de resíduos sólidos. As consequências para o meio ambiente são graves, causando a contaminação dos recursos naturais (água, solos, fauna e flora). Para Dias (2006), a deposição inadequada causa, além da poluição, a degradação ambiental, pois os sistemas naturais não conseguem metabolizar a grande quantidade de resíduos sólidos gerando impactos significativos no meio ambiente, os quais resultam em prejuízos à qualidade de vida de todos os seres.

Esta realidade, no entanto, pode ser constatada em outros municípios da Região Nordeste, como afirma a Associação Brasileira de Empresas de Limpeza Pública e Resíduos Especiais (ABRELPE, 2010), que aponta o Nordeste em segundo lugar, dentre as regiões brasileiras, na deposição inadequada de resíduos sólidos. Dados provenientes do Instituto 
Socioambiental (2008) revelam que 20\% do lixo produzido no Brasil são jogados em rios e várzeas. Segundo Silva e Liporone (2011), os resíduos sólidos podem apresentar vários problemas em relação ao seu acondicionamento e deposição, como o desenvolvimento de agentes patogênicos responsáveis pela proliferação de diversas doenças, constituindo-se em uma questão sanitária e de saúde pública.

Em relação ao acesso à água potável, verificou-se que apenas 54,4\% (26.406) da população são atendidos por serviços de abastecimento de água, fornecidos por prestadores de serviço ou órgãos municipais responsáveis pela gestão dos mesmos (SNIS, 2014). Ou seja, pouco mais da metade da população tem água nas condições de tratamento adequadas ao consumo, uma vez que o abastecimento por carros-pipa realizado na zona rural não é considerado condição apropriada para prover água à população, tendo em vista os riscos possíveis de contaminação da água, fornecimento do recurso não tratado, e outros problemas, sendo o ideal o abastecimento por meio de encanamentos oriundos de estações de tratamento.

Os resíduos de esgoto lançados no meio ambiente sem tratamento causam degradação ambiental, contaminando as águas de rios, açudes, e outras fontes de água potável, poluindo os solos, e assim concorrendo para afetar a vida da fauna e flora. Existem produtos químicos descartados no esgoto doméstico e industrial que são perigosos para a saúde humana e de diversas espécies de vida. Cavinatto (1992) define que a principal função do saneamento básico consiste em evitar a disseminação de doenças veiculadas por detritos originados de esgotos e lixos e no fornecimento de água com qualidade a população pelos gestores públicos.

\section{Desmatamento}

Este indicador pode ser analisado a partir da aplicação do NDVI, das incursões de campo e coleta de informações em órgãos públicos, proporcionando a compreensão da situação da conservação da vegetação no município. O NDVI é uma modelagem utilizada no estudo da vegetação, resultante da combinação dos níveis de reflectância da radiação nas bandas do vermelho e no infravermelho próximo das imagens de satélite, baseando-se no comportamento contrário da reflectância da vegetação na região do visível. Assim, quanto maior a densidade vegetacional, menor será a reflectância da vegetação em função da absorção da radiação pelos pigmentos fotossintetizantes das plantas (NOVO, 2008).

Moreira (2003) revela que a radiação global ao atingir a planta, interage com esta, resultando em três frações, sendo uma parte dessa radiação absorvida pelos pigmentos contidos na folha e participando da síntese de componentes ricos em energia, outra parte da radiação é refletida pelas folhas, fenômeno denominado de reflexão. Esta porção da radiação 
refletida pelas plantas corresponde à faixa que se aplica o NDVI. Uma terceira parte passa pelo processo de transmissão, através das camadas de folhas das plantas.

No estudo do índice de vegetação do município de Brejo da Madre de Deus, foram utilizadas as bandas 4 e 5, correspondentes ao vermelho e ao infravermelho-próximo, respectivamente, para se alcançar os dados (valores) do NDVI, como sugerido na metodologia desta modelagem. O resultado (Figura 2) mostrou valores no intervalo de -1 a 1 , no qual os valores mais próximos de 1 correspondem à maior presença de vegetação, já os valores próximos de -1 indicam incidência de solos descobertos, formações rochosas e recursos hídricos.

Os dados do raster de NDVI gerado a partir dos limites territoriais do município apresentaram variações significativas, conforme observado nas tonalidades das cores representadas na legenda da Figura 2, entre o vermelho, contemplando as áreas com baixa incidência de vegetação - solo exposto, água e rocha, e o verde escuro, correspondendo à vegetação densa. De acordo com Lourenço e Landim (2004), em cenas com vegetação o NDVI varia de 0,1 a 0,6 , onde os valores mais altos são associados a um maior vigor e densidade da cobertura vegetacional; a água e as nuvens apresentam reflectâncias maiores no visível do que no infravermelho, resultando em valores negativos no NDVI, já as rochas e solos têm reflectâncias similares nestas duas bandas e o índice de vegetação se aproxima de 0 .

Analisando os dados do índice de vegetação e através de visitas de campo, verificouse que as áreas não vegetadas se encontram nos núcleos urbanos, ao norte - Distrito de São Domingos, a sudoeste na sede do município e a sudeste no Distrito de Fazenda Nova. Na porção norte do município também se verificou a presença de atividade de pecuária extensiva, que contribui para a retirada da vegetação e degradação dos solos.

Figura 2: Índice de Vegetação do município de Brejo da Madre de Deus - PE. 


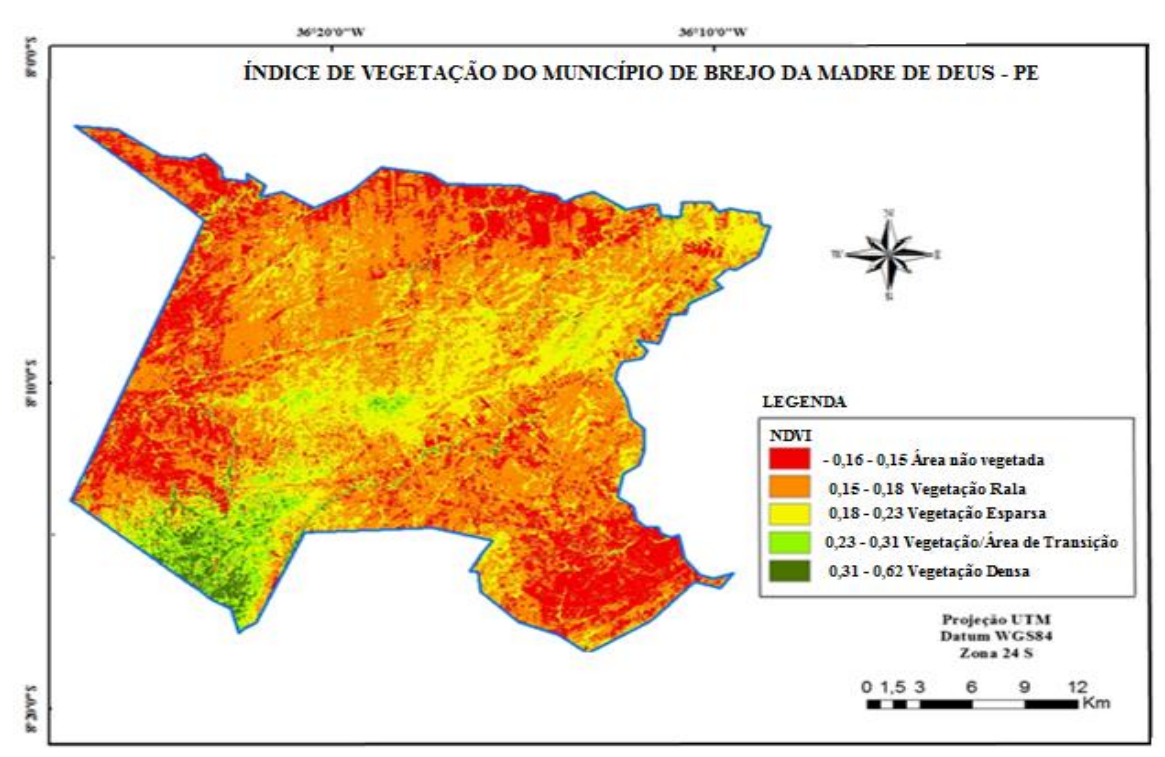

Fonte: Os autores, 2016.

As áreas de vegetação rala localizam-se em uma faixa de relevo menos acentuado com altitudes variando entre $300 \mathrm{~m}$ e $500 \mathrm{~m}$, correspondendo aos perímetros de várzeas próximos aos rios e riachos e outras áreas onde predominam a atividade agropecuária. Nestas áreas caracteriza-se o tipo de vegetação arbustiva arbórea aberta (caatinga).

Constatou-se o desmatamento nas áreas de várzeas nas margens do rio Laranjeiras, em virtude do desenvolvimento de agricultura irrigada, comprometendo as matas ciliares, e consequentemente, causando prejuízos ambientais. De acordo com Galvão (2000), as matas ciliares são aquelas que margeiam os corpos de água, como rios, riachos e lagoas, sendo importantes por influenciarem estes corpos de diversas maneiras e sua remoção causa prejuízos para o homem e a natureza. As matas ciliares protegem os cursos de água, evitando o seu assoreamento, além de servirem como habitat de diferentes espécies de animais e outros benefícios. Nesse aspecto, a manutenção desta vegetação é fundamental para o equilíbrio ecossistêmico, preservando o rio, os solos de seu entorno e a fauna.

As áreas de vegetação esparsa, de transição e densa correspondem às faixas de relevo de maior altitude, acima de $500 \mathrm{~m}$, onde se localizam as serras, destacando-se em toda a direção nordeste - sudoeste do município. Por serem locais de difícil acesso apresentam vegetação mais preservada. A região sudoeste do município apresenta um relevo acentuado acima de 1100 m de altitude e onde a vegetação é mais densa, caracterizando-se os tipos de vegetação arbustiva arbórea fechada e vegetação arbórea fechada, com altura média acima de 4 e 5 metros, respectivamente (SILVA FILHO et al., 1998). Esta relação entre relevo e vegetação no município de Brejo da Madre de Deus também foi verificada por Silva, 
Galvíncio e Pimentel (2008), que observaram um aumento aproximado de $56 \%$ da área de vegetação em decorrência da elevação da altitude.

É importante ressaltar que os dados analisados são do final do período seco no município, considerando-se, portanto, que as áreas fitofisiográficas apresentadas podem demonstrar alterações durante a estação úmida, em virtude das mudanças ocorridas na biomassa verde que se altera como resultado da adaptação ao clima semiárido, apresentando uma maior densidade foliar e de indivíduos durante este período (BRINA, 1998). Segundo Gurgel (2003), os valores de NDVI para a caatinga apresentam variações mais elevadas nos períodos entre dezembro e maio, estação chuvosa, proporcionando diferenças na cobertura vegetal.

Assim, verifica-se que as áreas mais degradadas correspondem aos estratos de vegetação de caatinga, onde se desenvolvem atividades agropecuárias de maneira insustentável, contribuindo para a substituição da cobertura vegetal. Esta situação também ocorre nas áreas de preservação permanente, principalmente nas áreas de várzeas próximas a rios e açudes e nas encostas das serras. Bezerra (1997), em pesquisa sobre a bacia do rio Laranjeiras, no município de Brejo da Madre de Deus, constatou o processo de degradação existente, devido a contaminação da bacia com efluentes oriundos de esgotos domésticos, produtos perigosos como cianeto e resíduos orgânicos de abatedouros de aves.

A figura 3A mostra o desenvolvimento da atividade agropecuária de maneira insustentável provocando a degradação dos solos e o desmatamento na região norte do município. A figura 3B apresenta a predominância desta atividade em áreas de preservação permanente, nas proximidades do rio Laranjeiras. O código florestal brasileiro - Lei 12.651/12 define áreas de preservação permanente, em seu art. 4 parágrafo I, afirmando o perímetro mínimo a ser preservado de vegetação no entorno dos cursos de água: "as faixas marginais de qualquer curso d'água natural perene e intermitente, excluídos os efêmeros, desde a borda da calha do leito regular, em largura mínima de: a) 30 (trinta) metros, para os cursos d'água de menos de 10 (dez) metros de largura". 
Figuras 3A e 3B: Degradação do solo e vegetação rala em propriedade na zona rural; Agropecuária em área de várzea, Brejo da Madre de Deus - PE.

3A

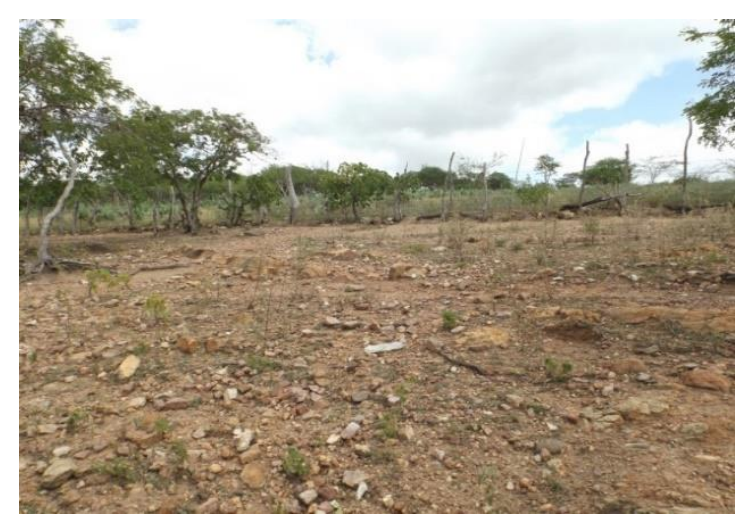

3B

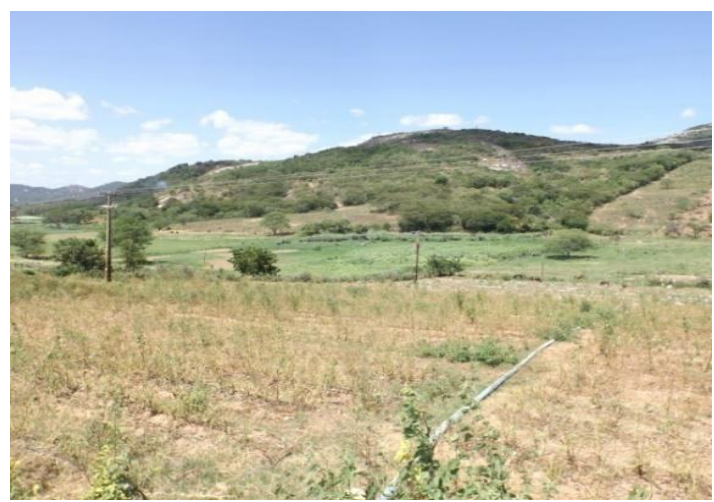

Fonte: Os autores.

Nesse sentido, compreende-se que a transformação das paisagens naturais, através de práticas insustentáveis, traz consequências graves para os sistemas ambientais, provocando o aumento do desmatamento, intensificação dos processos erosivos, poluição dos solos e dos corpos hídricos. Além do mais, é importante ressaltar as peculiaridades fitopedológicas do ambiente semiárido que requerem um manejo adaptado às suas condições. Segundo Ab'Saber (2003), os rios do semiárido estão sob solos rasos e pouco permeáveis, dificultando o armazenamento de água na região. O tipo de vegetação xerófila (caatinga) não proporciona um manto protetor ao solo, causando ainda mais a perda de água e a sua erosão (ALVES; AZEVEDO, 2013).

\section{Extração de Areia em Leitos de Rios}

A extração irregular de areia em leitos de rios tem sido prática frequente, de acordo com informações da Assessoria da Secretaria de Agricultura e Abastecimento de Brejo da Madre de Deus (2016). Os impactos da retirada de areia nos leitos dos rios são diversos, causando danos no solo, fauna e flora. Nogueira (2016) listou os principais impactos da atividade em suas diversas fases de execução (instalação, operação e desativação do empreendimento), dentre eles destacam-se os principais problemas referentes à operação da extração: depreciação da qualidade do ar; incidência de processos erosivos; diminuição da infiltração do solo; aumento da concentração de partículas em suspensão nos corpos d'água; desregularização da vazão dos cursos de água; danos à microbiota do solo. 
Nesse aspecto, considera-se a extração de areia atividade com elevado potencial de degradação dos recursos naturais, causando perturbação ambiental e consequente desequilíbrio dos ecossistemas, necessitando, portanto, de medidas de fiscalização, visando coibir a prática irregular no município.

\section{$\underline{\text { Uso de Agrotóxicos e Insumos Químicos }}$}

O município de Brejo da Madre de Deus destaca-se na atividade agrícola, sendo importante produtor de olerícolas (cenoura, tomate, dentre outras) no estado de Pernambuco. Segundo Silva (2012, p.66), "o uso da terra observado no município é majoritariamente para o cultivo de olerícolas de ciclo curto e com uso intenso de herbicidas e inseticidas nas culturas de beterraba, cenoura, tomate, repolho, alface e pimentão".

As décadas de 1970 e 1980 apresentaram um aumento expressivo da produção agrícola municipal, principalmente no cultivo da cenoura, em virtude de créditos e financiamentos. $\mathrm{O}$ uso intensivo de agrotóxicos na produção agrícola é prática corrente entre os agricultores (SILVA, 2012; ASSESSORIA DA SECRETARIA DE AGRICULTURA E ABASTECIMENTO DE BREJO DA MADRE DE DEUS, 2016).

A partir da década de 1990 a atividade olerícola passou a declinar no município, fato esse ocasionado pelas práticas agrícolas predatórias, com uso intensivo de insumos químicos, ocorrência de erosão e limitação da disponibilidade de água para irrigação e também a concorrência com outros municípios produtores (SILVA, 2012). O resultado é a degradação do meio ambiente, através da poluição dos corpos hídricos, exaustão e erosão dos solos.

O uso desordenado dos recursos naturais ocasiona sérios riscos ao equilíbrio dos ecossistemas. As atividades agrícolas desenvolvidas de maneira insustentável vêm causando impactos socioambientais no município, comprometendo o estado do meio ambiente. Nesse sentido, faz-se necessário a realização de mudanças no desenvolvimento da agricultura, através de ações planejadas por parte do poder público que promovam orientações e assistência técnica aos agricultores sobre o uso adequado da terra e produção agrícola sustentável; o monitoramento ambiental.

\section{Resposta}

Os indicadores relacionados à dimensão resposta contemplam as ações empreendidas pelos órgãos públicos para mitigar os problemas ambientais no âmbito municipal. É importante ressaltar a importância da realização de ações efetivas que possam contribuir para 
a sustentabilidade ambiental, promovendo a qualidade de vida da população e o uso adequado dos recursos naturais.

Planos de Saneamento Básico e Resíduos Sólidos

O município de Brejo da Madre de Deus faz parte do Consórcio Público Intermunicipal do Agreste Pernambucano e Fronteiras. Este consórcio "foi criado em 2012 com o objetivo de ajudar os municípios localizados na fronteira da Paraíba e no Agreste pernambucano" (CONIAPE, 2016). Através do consórcio é possível estabelecer ações integradas que possibilitem o desenvolvimento dos territórios envolvidos, compartilhando de decisões que visem solucionar problemas vivenciados por todos os atores sociais como as questões que envolvem saúde pública, tratamento dos resíduos sólidos, saneamento básico, emprego, dentre outras.

Por meio do consórcio foi providenciada a elaboração do Plano de Gestão Integrada de Resíduos Sólidos - PGIRS pelo Instituto de Desenvolvimento Social e Tecnológico, contratado através de concorrência pública realizada com esta finalidade. Os municípios beneficiados inicialmente pelo plano foram: Bom Jardim, Brejo da Madre de Deus, Casinhas, Frei Miguelinho, João Alfredo, Orobó, Riacho das Almas, Santa Cruz do Capibaribe, Santa Maria do Cambucá, São Caetano, Surubim, Taquaritinga do Norte, Toritama e Vertente do Lério, em Pernambuco, totalizando 14 municípios beneficiados pelo PGIRS (CONIAPE, 2016).

Em um primeiro momento foram realizadas visitas técnicas, resultando na elaboração de um diagnóstico ambiental. A partir do diagnóstico foram desenvolvidos os planejamentos e ações a serem atendidos pelos municípios. A aprovação do plano de resíduo nas câmaras legislativas municipais também fez parte desta primeira etapa. Os primeiros municípios a aprovarem o PGIRS nas câmaras legislativas foram: Taquaritinga do Norte, Bom Jardim, Brejo da Madre de Deus (Lei nº 389/2016), Santa Maria do Cambucá e Orobó. Atualmente os municípios consorciados destinam os seus resíduos sólidos nos lixões, com exceção de Santa Cruz do Capibaribe, que tem um aterro sanitário controlado. O objetivo do PGIRS é a instalação de aterros sanitários integrados, onde possam ser tratados adequadamente os resíduos sólidos (CONIAPE, 2016).

Brejo da Madre de Deus elaborou o plano de saneamento básico municipal, que assim como o plano de resíduos sólidos, ainda não está em execução, sendo todos os resíduos 
de esgotos despejados no meio ambiente (ASSESSORIA DA SECRETARIA DE AGRICULTURA E ABASTECIMENTO DE BREJO DA MADRE DE DEUS, 2016).

\section{$\underline{\text { Reflorestamento de APP's e Projetos de Educação Ambiental }}$}

As ações visando à proteção das áreas de nascentes, áreas desmatadas e de vertentes, consistem no reflorestamento com mudas nativas da região. Estas mudas são cultivadas em uma sementeira mantida pelos órgãos públicos do município de Brejo da Madre de Deus. O reflorestamento faz parte de projetos desenvolvidos pelos órgãos públicos junto à comunidade, visando à orientação sobre a importância dessas áreas e a necessidade de preservação das mesmas (ASSESSORIA DA SECRETARIA DE AGRICULTURA E ABASTECIMENTO DE BREJO DA MADRE DE DEUS, 2016).

A realização de projetos de educação ambiental também faz parte das ações que objetivam a preservação ambiental. Estes projetos são realizados nas escolas e também com os produtores rurais, através da orientação em relação ao uso adequado dos recursos naturais. Um dos projetos é a Feira do Verde, realizada anualmente, contemplando um tema específico de importância socioambiental, envolvendo escolas e sociedade civil em torno da questão ambiental. Este ano (2016) o tema da Feira do Verde foi: “Agrofloresta: alternativa para produção agrícola e preservação das nascentes e rios".

A atuação do CONIAPE também objetiva a realização de atividades de educação ambiental nos municípios consorciados. A principal referência para a educação socioambiental nos municípios que fazem parte do consórcio é a Cartilha "Lixo: quem se lixa?", que deve ser disponibilizada nos sites das prefeituras, tendo em vista a divulgação e educação socioambiental, tendo como público-alvo os estudantes das escolas municipais, beneficiando cerca de 75.164 alunos em 527 escolas. Além disso, o CONIAPE visa desenvolver ações junto às Secretarias de Educação dos municípios, como a promoção de formação continuada para professores, dando suporte no planejamento e elaboração de projetos educativos, na articulação com as comunidades e o monitoramento das atividades realizadas (CONIAPE, 2016).

\section{Fiscalização Ambiental e Fundo Municipal de Meio Ambiente}

A fiscalização ambiental é realizada com a finalidade de coibir as ações predatórias sobre o meio ambiente. As principais atividades de fiscalização compreendem a extração de areia em leitos de rios, o desmatamento e o controle de fumaças lançadas no ar pelas padarias. 
A remuneração obtida com as multas aplicadas aos agentes degradadores do meio ambiente é revertida para o Fundo Municipal de Meio Ambiente, que utiliza o dinheiro em ações de preservação ambiental (ASSESSORIA DA SECRETARIA DE AGRICULTURA E ABASTECIMENTO DE BREJO DA MADRE DE DEUS, 2016).

\section{Extensão Rural e Regularização do Cadastro Ambiental Rural}

As atividades de extensão rural são realizadas por diferentes órgãos públicos e organizações não-governamentais, como o Sindicato de Trabalhadores/as Rurais do Município de Brejo da Madre de Deus, o Instituto Agronômico de Pernambuco (IPA), a Organização Não-Governamental - SERTA (Serviço de Tecnologia Alternativa), que tem convênio para prestar assistência técnica por três anos (2014-2017) e a AMAS - Associação Menonita de Assistência Social. Em relação ao cadastro ambiental rural - CAR, o município tem realizado o cadastro das propriedades rurais, tendo em vista regularizá-las mediante os ordenamentos do Código Florestal Brasileiro (Lei 12.651 de 25 de maio de 2012) em vigência. (ASSESSORIA DA SECRETARIA DE AGRICULTURA E ABASTECIMENTO DE BREJO DA MADRE DE DEUS, 2016).

\section{$\underline{\text { Participação em Conselho de Desenvolvimento Sustentável Municipal - CONDESB }}$}

O Conselho de Desenvolvimento Sustentável de Brejo da Madre de Deus é uma entidade da sociedade civil autônoma, que objetiva colaborar com o desenvolvimento local sustentável e apoiar a descentralização das políticas públicas municipais (BREJO DA MADRE DE DEUS, 2001). Neste Conselho participam representantes dos órgãos públicos, que frequentam as reuniões realizadas mensalmente (terceira quarta-feira de cada mês), contribuindo para as discussões sobre as temáticas de interesse do desenvolvimento local e o planejamento de ações tomadas nesse sentido (ASSESSORIA DA SECRETARIA DE AGRICULTURA E ABASTECIMENTO DE BREJO DA MADRE DE DEUS, 2016).

\section{CONSIDERAÇÕES FINAIS}

De modo geral, considera-se que as respostas verificadas para o município de Brejo da Madre de Deus são importantes, porém não são suficientes para atenuar os efeitos socioambientais provocados pela utilização inadequada dos recursos naturais, resultando em pressões sobre o meio ambiente. As ações de resposta apresentam-se em níveis embrionários, possuindo uma abrangência pouco significativa, caracterizando-se como medidas pontuais, 
tendo em vista que não se constituem em uma política ambiental de ação planejada no âmbito municipal. As incursões de campo foram fundamentais para compreender os resultados analisados. Constatou-se que não existe um órgão específico responsável por planejar as ações ambientais, sendo a Secretaria de Agricultura e Abastecimento, com os poucos recursos e técnicos que possui, designada para responder às demandas de sua área e às ambientais.

Portanto, faz-se necessário a aplicação efetiva de políticas públicas que possam avançar no sentido de promover o desenvolvimento sustentável local, assim como a ampliação das ações que já existem, buscando solucionar os problemas descritos na área de estudo. A instalação de um órgão responsável pelo planejamento e gestão das políticas ambientais é imprescindível, visando o estabelecimento de um sistema de monitoramento ambiental que possibilite assegurar a manutenção da qualidade dos recursos naturais.

O método PER mostrou-se adequado para o estudo da temática abordada, tendo em vista que a sistematização e caracterização dos problemas evidenciados nos indicadores de pressão e estado com as respectivas respostas mitigadoras tomadas pelos órgãos públicos constituem-se nos primeiros passos, importantes para avaliar estas ações, bem como para o estabelecimento de políticas de planejamento e gestão ambiental. Os resultados obtidos têm como finalidade proporcionar uma melhor atuação dos agentes públicos mediante a formulação de propostas que venham melhorar a qualidade ambiental diagnosticada.

Finalmente, ressalta-se que as respostas necessárias para solucionar os problemas verificados nas dimensões de pressão e estado requerem políticas eficazes e um tempo considerável, em virtude da regeneração do equilíbrio ambiental, tendo em vista que a natureza tem o seu período de recuperação. Ademais, é importante a realização de estudos complementares que possam agregar outros indicadores de modo a fornecer informações mais detalhadas da situação ambiental no município.

\section{AGRADECIMENTOS}

Os autores agradecem à FACEPE pelo apoio financeiro concedido à primeira autora, através de bolsa de mestrado e à Prefeitura de Brejo da Madre de Deus, pelas informações prestadas, importantes para a realização desta pesquisa. 


\section{REFERÊNCIAS}

ABRELPE. Associação Brasileira de Empresas de Limpeza Pública e Resíduos Especiais.

Panorama dos resíduos sólidos no Brasil - 2007. Disponível em: $<$ http://www.abrelpe.org.br/panorama_2007.php $>$. Acessado em 10 de setembro de 2016. AB' SABER, A. N. Os domínios de natureza no Brasil: potencialidades paisagísticas. 3. ed. São Paulo: Ateliê Editorial, 2003.158 p.

ALVES, T. L. B.; AZEVEDO, P. V. de. Caracterização dos efeitos das secas no semiárido paraibano. 2013. Disponível em: <http://expedicaosemiarido.org.br/wpcontent/uploads/2013/08/Artigo-Telma.pdf>. Acessado em 20 de agosto de 2016.

ASSESSORIA DA SECRETARIA DE AGRICULTURA E ABASTECIMENTO DE BREJO DA MADRE DE DEUS - PE. Sustentabilidade e desenvolvimento sustentável em Brejo da Madre de Deus - PE. Brejo da Madre de Deus, Pernambuco, Junho de 2016. Entrevista concedida aos autores desta pesquisa.

BAKKES, J. A.; van den BORN, G. J.; HELDER, J. C.; SWART, R. J.; HOPE, C. W.; PARKER, J. D. E. An overview of environmental indicators: State of the art and perspectives. UNEP/EATR. 94-01; RIVM/402001001. Environmental Assessment SubProgramme; UNEP, Nairobi, 1994.

BEZERRA, S. M. da C. Diagnóstico ambiental preliminar da bacia hidrográfica do rio Laranjeiras - Brejo da Madre de Deus - Pernambuco. In: Anais do $19^{\circ}$ Congresso Brasileiro de Engenharia Sanitária e Ambiental. Foz do Iguaçu (PR): Associação Brasileira de Engenharia Sanitária e Ambiental, p.1974-1984, 1997.

BRAGATTO, R. D.; MARTINI, C. A.; STEFFANI, M. A.; ZOREL JÚNIOR, H. E.; BARRETO, R. M. Indicadores ambientais de sustentabilidade sistematizados pelo modelo pressão-estado-resposta (PER): análise das águas superficiais na microbacia hidrográfica passo da pedra, em Pato Branco - PR. Revista Brasileira de Agroecologia, Porto Alegre,7(2), 87-103, (2012).

BRASIL, Lei 12.651/12, de 25 de maio de 2012. Dispõe sobre a proteção da vegetação nativa. Disponível em: $<$ http://www.planalto.gov.br/ccivil_03/_ato2011-

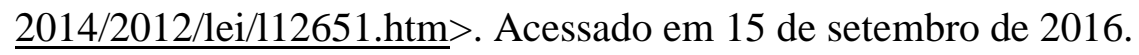

BRASIL. MINISTÉRIO DE MINAS E ENERGIA/CPRM - Serviço Geológico do Brasil. Diagnóstico do município de Brejo da Madre de Deus, estado de Pernambuco. Editores: BELTRÃO, B. A.; MASCARENHAS, J. C.; MIRANDA, J. L. F.; SOUZA JUNIOR, L. C.; 
GALVÃO, M. J. T. G.; PEREIRA, S.N. Projeto cadastro de fontes de abastecimento por água subterrânea. Recife: CPRM/PRODEEM, 2005. 21p.

BRINA, A. E. Aspectos da dinâmica da vegetação associada a afloramentos calcários na APA Carste de Lagoa Santa, MG. Dissertação (Conservação e Manejo da Vida Silvestre). Universidade de Minas Gerais - Ecologia,1998. 107p.

CARVAlHO, P. G. M. de; BARCEllos, F. C; MOREIRA, C. G. Políticas públicas para meio ambiente na visão do gestor ambiental- Uma aplicação do modelo PER para o SemiÁrido. In.: Anais do VII Encontro da Sociedade Brasileira de Economia Ecológica Fortaleza, 28 a 30 de novembro de 2007.

CARVAlHO, P. G. M. de; BARCEllos, F. C.; GREEN, A. L.; OLIVEIRA, S. M. M. de. Indicadores para a avaliação da gestão ambiental municipal com base no modelo pressãoestado-resposta. Anais do XVI Encontro Nacional de Estudos Populacionais - ABEP. Caxambú- MG - Brasil, p. 1-20, 2008.

CAVINATTO, V. M. Saneamento básico: fonte de saúde e bem-estar. São Paulo: Moderna, 1992.

CONSÓRCIO PÚBLICO INTERMUNICIPAL DO AGRESTE PERNAMBUCANO E FRONTEIRAS - CONIAPE. Resumo do plano intermunicipal de resíduos sólidos. 2016. Disponível em: <http://consorcioconiape.pe.gov.br/wp-content/uploads/2016/11/ResumoPlano-de-Res\%C3\%Adduos.pdf>. Acessado em 10 de novembro de 2016.

COUTO, O. F. V. Geração de um índice de sustentabilidade ambiental para bacias hidrográficas em áreas urbanas através do emprego de técnicas integradas de geoprocessamento. Dissertação (Mestrado em Geografia). Instituto de Geociências, UFRGS. Porto Alegre, 2007.

DIAS, G. F. Educação e Gestão Ambiental. São Paulo: Editora Gaia, 2006.

GAlVÃO, A. P. M.. Reflorestamento de Propriedades Rurais para fins Produtivos e Ambientais: um guia para ações municipais e regionais. Brasília: Embrapa Comunicação para Transferência de tecnologia; Colombo, PR: Embrapa Florestas, 2000.

GOMES, P. R; MALHEIROS, T. F. Proposta de análise de indicadores ambientais para apoio na discussão da sustentabilidade. Revista Brasileira de Gestão e Desenvolvimento Regional, Taubaté, v. 8, n. 2, p. 151-169, mai-ago/2012.

GURGEL, H. da C. Estudo da variabilidade do NDVI sobre o Brasil, utilizando-se a análise de agrupamentos. Revista Brasileira de Engenharia Agrícola e Ambiental, Campina Grande, v. 7, n.1, p. 85-90, 2003. 
HAMMOND, A.; ADRIAANSE, A.; RODENBURG, E.; BRYANT, D.; WOODWARD, R. Environmental indicators: A systematic approach to measuring and reporting on environmental policy performance in the context of sustainable development. Washington, D.C.: World Resources Institut, 1995.

INSTITUTO SÓCIO AMBIENTAL. Almanaque Brasil Socioambiental: 2008. 2 ed. São Paulo, SP. 2007. 552p.

KEMERICH, P. D. da C.; RITTER, L. G.; BORBA, W. F. Indicadores de sustentabilidade ambiental: métodos e aplicações. Revista Monografias Ambientais - Remoa, Santa Maria, v. 13, n.5, edição especial, p.3723-3736, 2014.

LOURENÇO, R. W.; LANDIM, P. M. B. Estudo da variabilidade do "índice de vegetação por diferença normalizada/NDVI" utilizando kriagem indicativa. H. Environ., 4(1), p. 38-55, 2004.

MARTINEZ, R. Indicadores de Sostenibilidad Ambiental y de Desarrollo Sostenible: Estado del Arte y Perspectivas. Santiago de Chile: Série Manuales, nº 16. CEPAL, 2001. $116 \mathrm{p}$.

MARZAL, K; ALMEIDA, J. Indicadores de sustentabilidade para agroecossistemas: Estado da arte, limites e potencialidades de uma nova ferramenta para avaliar o desenvolvimento sustentável. Cadernos de Ciência \& Tecnologia, Brasília, v.17, n.1, p.41-59, jan./abr. 2000. MINISTÉRIO DAS CIDADES - Sistema Nacional de Informações sobre Saneamento (SNIS). Dados de saneamento de 2014. Disponível em: <http://app.cidades.gov.br/serieHistorica/>. Acessado em 21 de junho 2016.

Dados de saneamento de 2013. Disponível em: <http://app.cidades.gov.br/serieHistorica/>. Acesso em: 20 de junho 2016.

MELO, J. S. Dinâmica geomorfológica do ambiente de encosta em Brejo da Madre de Deus - PE: Uma abordagem a partir da perspectiva morfoestratigráfica aplicada aos depósitos coluviais. Dissertação (Mestrado em Geografia). UFPE - Recife, 2008.

MELO, S. C. Estrutura, petrologia e geocronologia do batólito Brejo da Madre de Deus (estado de Pernambuco), relações com a zona de cisalhamento Pernambuco leste, Nordeste do Brasil. Tese (Doutorado em Geociências). UFPE - Recife, 2002.

MOREIRA, M. A. Fundamentos do sensoriamento remoto e metodologias de aplicação. 2.ed. Viçosa - MG: UFV, 2003. 307 p. 
NOGUEIRA, G. R. F. A extração de areia em cursos de água e seus impactos: proposição de uma matriz de interação. Trabalho Final de Curso (Engenharia Sanitária e Ambiental). Universidade Federal de Juiz de Fora, UFJF, 2016.

NOVO, E. M. L. de M. Sensoriamento Remoto: princípios e aplicações. 3ed. São Paulo: Blucher, 2008.

OECD - ORGANIZATION FOR ECONOMIC COOPERATION AND DEVELOPMENT. Environmental indicators: development, measurement and use. Paris: Organização para a Cooperação e o Desenvolvimento Econômico; 2003.

Environmental indicators. Paris: OECD, 1993.

SILVA, D. G. da. Evolução paleoambiental dos depósitos de tanques em Fazenda Nova, município de Brejo da Madre de Deus - Pernambuco. Dissertação (Mestrado em Geografia). UFPE - Recife, 2007.

SILVA, M. D. da.; GALVÍNCIO, J. D.; PIMENTEL, R. M. de M. Diagnóstico da ocupação vegetacional do município de Brejo da Madre de Deus, Pernambuco, Brasil, através do sensoriamento remoto. Revista Brasileira de Geografia Física, Recife, v.1, n. 2, set/dez., p. 15-29, 2008.

SILVA, C. B. da; LIPORONE, F. Deposição irregular de resíduos sólidos domésticos em Uberlândia: algumas considerações. Observatorium: Revista Eletrônica de Geografia, Uberlândia, v.2, n.6, abr., p.22-35, 2011.

SILVA, G. C. da. Uso de agrotóxicos e impactos no espaço agrário de Brejo da Madre de Deus (PE). Dissertação (Mestrado em Geografia). UFPE - Recife, 2012.

SILVA FILHO, A. A.; TONIOLO, E. R.; GABÍNIO, M.; OLIVEIRA, S. F. S. Mapeamento da cobertura florestal nativa lenhosa do estado de Pernambuco (Documento de Campo FAO nº17). PNUD/FAO/IBAMA, Governo de Pernambuco, Recife, 1998. 32p.

SOUZA, J. L.; SILVA, I. R. Utilização do modelo pressão-estado-resposta na avaliação da qualidade das praias da Ilha de Itaparica, Bahia. Caderno de Geociências, Salvador, v.11, n.1-2, novembro, p. 103-113, 2014.

VAN BELLEN, H. M. Indicadores de Sustentabilidade: uma análise comparativa. 2002. Tese (Doutorado em Engenharia de Produção). UFSC, Florianópolis, 2002. 